\title{
Left Seminal Vesicle
}

National Cancer Institute

\section{Source}

National Cancer Institute. Left Seminal Vesicle. NCI Thesaurus. Code C128598.

The seminal gland that is located to the anatomical left of the bladder. 